\title{
Pelatihan Desain Grafis Untuk Guru SMP Negeri 3 Mendo Barat Bangka
}

\author{
Sidhiq Andriyanto ${ }^{1 *}$, Ahmat Josi ${ }^{2}$ \\ 1,2Teknologi Rekayasa Perangkat Lunak, Politeknik Manufakur Negeri Bangka Belitung, Indonesia \\ Email: ${ }^{1}$ sidhiqpolman@gmail.com, ${ }^{2}$ ahmatjosi@gmail.com
}

\section{INFORMASI ARTIKEL}

\section{Data artikel:}

Naskah masuk, 11 Oktober 2020

Direvisi, 24 Desember 2020

Diterima,25 Desember 2020

\section{Kata Kunci:}

Training,

Design,

Skill,

Teacher

\begin{abstract}
ABSTRAK
Abstract- This community service activity aims to provide graphic design training for teachers. Through graphic design training, it is hoped that it can provide many benefits to teachers to add skills and present innovative and attractive learning media. This community service activity begins with a survey to partner locations, planning activities, compiling training materials, then implementing training. This activity was held at SMP Negeri 3 Mendo Barat, Bangka. The time for this training is two days. The result of this community service activity was graphic design training for teachers which went well with the improvement of skills in the field of information technology.
\end{abstract}

\begin{abstract}
Abstrak- Kegiatan pengabdian masyarakat ini bertujuan untuk memberikan pelatihan desain grafis untuk para guru. Melalui pelatihan desain grafis diharapkan dapat memberikan banyak manfaat kepada guru untuk menambah keterampilan dan menyajikan media pembelajaran yang inovatif serta menarik. Kegiatan pengabdian masyarakat ini dimulai dengan survei ke lokasi mitra, merencanakan kegiatan, penyusunan materi pelatihan, kemudian pelaksanaan pelatihan. Kegiatan ini diselenggarakan di SMP Negeri 3 Mendo Barat, Bangka. Waktu pelaksanaan pelatihan ini adalah dua hari. Hasil kegiatan pengabdian kepada masyarakat ini adalah pelatihan desain grafis untuk para guru yang berjalan dengan baik dengan adanya peningkatan keterampilan di bidang teknologi informasi.
\end{abstract}

Korespondensi:

Sidhiq Andriyanto

Program Studi Teknologi Rekayasa Perangkat Lunak, Politeknik Manufaktur Negeri Bangka Belitung Kawasan Industri Airkantung, Sungailiat, Bangka, Indonesia

\section{PENDAHULUAN}

Era globalisasi seperti saat ini kemajuan teknologi berkembang pesat yang dapat membantu manusia melakukan interaksi dengan manusia lainnya tanpa ada batasan jarak dan waktu. Kemajuan teknologi tersebut memberikan kemudahan terhadap berbagai aspek kehidupan, mulai dari dunia bisnis hingga dunia pendidikan. Salah satu bentuk teknologi yang berperan penting dalam memudahkan dan membantu manusia adalah komputer (Rais, 2018). 
Pembaharuan diterapkan di berbagai bidang tanpa terkecuali bidang industri kreatif seperti pengolahan gambar digital, percetakan, dan desain grafis. Hal tersebut menuntut para pengguna untuk selalu mengikuti perkembangan dan mampu memanfaatkan teknologi informasi secara maksimal termasuk dalam dunia pendidikan. Dalam pembelajaran, pengajar pun dituntut untuk menyajikan media menarik bagi para siswa (Wanti \& Tripustikasari, 2019).

SMP Negeri 3 Mendo Barat merupakan salah satu sekolah menengah pertama yang berada di desa Rukam, kecamatan Mendo Barat, kabupaten Bangka, provinsi Kepulauan Bangka Belitung. Lokasi sekolah ini dinilai cukup jauh dari perkotaan. Namun, sekolah ini tetap mengutamakan proses pembelajaran yang berkualitas dengan memanfaatkan sarana dan prasarana yang ada. Salah satu fasilitas yang dapat dimiliki yaitu laboratorium komputer yang dapat digunakan para guru dan siswa dalam pelaksanaan proses pembelajaran.

Para guru di SMP Negeri 3 Mendo Barat memiliki semangat tinggi dalam memberikan pengajaran kepada siswa-siswanya. Namun para guru menilai bahwa minat siswa menurun dalam belajar. Kepala UPTD SMP Negeri 3 Mendo Barat berharap kepada para guru untuk memberikan inovasi dalam kegiatan pembelajaran. Supaya siswa berminat dan semangat kembali dalam proses pembelajaran.

Melalui diskusi yang telah dilakukan, permasalahan yang dimiliki mitra adalah menurunnya minat siswa dalam mengikuti proses pembelajaran. Karena cara penyampaian materi yang kurang menarik dan membosankan bagi siswa. Oleh karena itu perlunya pemanfaatan teknologi informasi dalam proses penyampaian materi pembelajaran supaya terlihat menarik dan inovatif.

Berdasarkan masalah tersebut, solusi yang dapat ditawarkan adalah mengadakan sebuah pelatihan yang memanfaatkan aplikasi grafis.
Karena gambar adalah dasar dari penyampaian materi secara kreatif dan inovatif. Pelatihan desain grafis ini ditujukan untuk para guru agar memiliki kompetensi tambahan dan dapat diterapkan dalam kegiatan pembelajaran.

Pelatihan merupakan sebuah proses pembelajaran yang lebih banyak dalam proses praktik daripada proses teori yang dilakukan pelatih baik mandiri maupun kelompok dengan tujuan meningkatkan kompetensi atau kemampuan dari seseorang atau kelompok. Tujuan utamanya adalah agar individu atau kelompok tersebut menguasai keterampilan terhadap materi pelatihan. Ada beberapa jenis pelatihan seperti pelatihan keterampilan, wacana, dan soft skill. Ciri-ciri pelatihan yaitu terdapat sebuah proses yang bertujuan untuk meningkatkan penguasaan keterampilan tertentu, ketepatan dan kesesuaian materi yang perlu disampaikan, waktu pelatihan yang ditetapkan, dan proses pelatihan dilakukan dengan mempelajari serta melakukan proses (Purwati \& Perdanawanti, 2019).

Desain grafis merupakan proses komunikasi yang menggunakan elemen visual, seperti tulisan, bentuk, dan gambar yang dimaksudkan untuk menciptakan persepsi akan suatu pesan yang disampaikan. Visual yang tercipta diharapkan dapat menjadi sarana penyampaian informasi atau pesan secara jelas dan efektif, bahkan mampu membentuk persepsi manusia akan sebuah hal. Awalnya desain grafis hanya diterapkan untuk media massa, seperti brosur, majalah, dan buku. Namun, karena semakin maju perkembangan teknologi, desain grafis diterapkan juga ke dalam media elektronik. Istilah yang sering digunakan adalah desain interaktif atau desain multimedia (Budiarto, 2019).

Aplikasi desain grafis yang digunakan adalah aplikasi Corel Draw. Corel Draw X7 merupakan salah satu aplikasi yang dapat digunakan untuk pembuatan desain grafis dalam bentuk vektor. Corel Draw dibuat oleh perusahaan perangkat lunak Corel yang berada 
di Ottawa, Kanada. Aplikasi ini adalah program pengolah desain grafis yang sering digunakan dan diminati oleh para desainer grafis. Corel Draw mudah digunakan karena memiliki tool (alat) dan efek yang bisa menghasilkan berbagai bentuk desain yang inovatif dan ekspresif serta dilengkapi komposisi warna yang bagus. Di dalamnya juga terdapat tool untuk membuat objek yang unik dan kreatif (Budiarto, 2019).

Unsur dasar pada disiplin desain lain juga dimiliki oleh desain grafis. Unsur yang dimaksud antara lain garis, form, bentuk(shape), tekstur, warna, dan ruang. Semua unsur diatur sedemikian rupa sehingga membentuk prinsip dasar dari desain visual. Elemen prinsip tersebut antara lain adalah keseimbangan (balance), tekanan (emphasis), ritme (rhythm), kesatuan (unity), dan proporsi (proportion), yang membentuk komposisi yang luas (Rais, 2018).

Dalam proses pelatihan, narasumber menjelaskan tata cara penggunaan aplikasi Corel Draw. Setelah itu para guru atau peserta akan praktik sesuai arahan dari narasumber. Peserta dibimbing untuk membuat beberapa bentuk gambar vector yakni bentuk dasar seperti kotak, lingkaran, dan lainnya. Setelah itu manipulasi bentuk dasar dengan menggunakan shape tool, menambah tulisan dan gambar raster. Untuk penugasan mandiri yang diberikan adalah pembuatan sertifikat.

Dalam pelatihan desain grafis ini para guru akan diberikan modul pelatihan cetak dan e-book untuk memudahkan para guru memahami penggunaan aplikasi desain grafis.

\section{METODE PELAKSANAAN}

Beberapa tahapan yang dilakukan dalam pelaksanaan pengabdian kepada masyarakat ini antara lain survei ke lokasi mitra, menyusun perencanaan kegiatan, membuat materi pelatihan dan pelaksanaan kegiatan pelatihan.
Pelaksanaan kegiatan ini bertempat di ruang aula SMP Negeri 3 Mendo Barat yang pesertanya adalah para guru di sekolah tersebut. Kegiatan ini dilaksanakan dalam waktu dua hari. Para peserta berasal dari guru dan staf SMP Negeri 3 Mendo Barat dengan penambahan beberapa guru sekolah dasar yang berada kecamatan tersebut. Banyaknya peserta adalah 25 orang.

Metode kegiatan adalah pelatihan dengan menggunakan komputer dengan fokus desain grafis. Aplikasi desain grafis yang digunakan adalah Corel Draw X7.

Materi pelatihan disampaikan dalam waktu kurang lebih 45 menit dan kemudian dilanjutkan praktik dengan pendampingan pada setiap peserta. Peserta diarahkan untuk membuat objek bentuk dasar, membuat gambar sederhana, memodifikasi tulisan, memberi warna dan pembuatan sertifikat.

\section{HASIL DAN PEMBAHASAN}

Sebelum pelatihan desain grafis dilaksanakan, para guru SMP Negeri 3 Mendo Barat belum memiliki keterampilan tentang desain grafis menggunakan aplikasi Corel Draw. Keterampilan desain grafis ini dapat dimanfaatkan untuk membuat gambar sebagai penunjang bahan ajar yang kreatif dan inovatif. Peserta dapat membuat poster, brosur, banner, sertifikat, dan sebagainya.

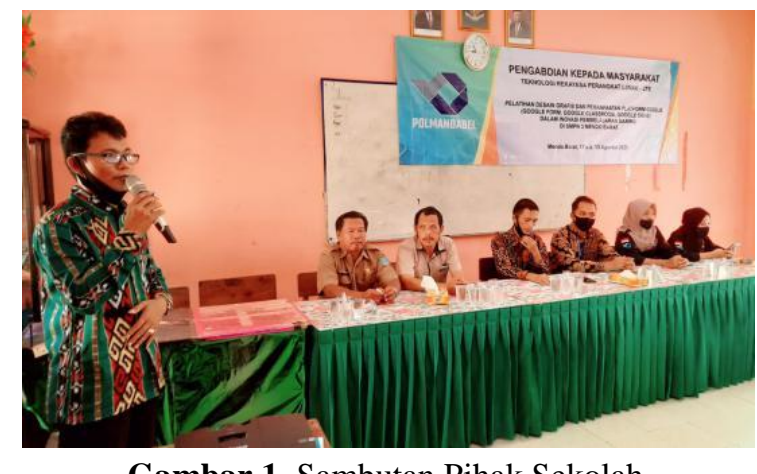

Gambar 1. Sambutan Pihak Sekolah

Sambutan dari pihak sekolah atas kegiatan pelatihan desain grafis yang dihadiri oleh satuan pengawas sekolah di kecamatan Mendo 
Barat. Materi pelatihan dalam kegiatan diberikan oleh Dosen Diploma IV Teknologi Rekayasa Perangkat Lunak dari Politeknik Manufaktur Negeri Bangka Belitung dan dibantu beberapa mahasiswa TRPL.

Para peserta dibekali modul pelatihan tercetak dan e-book sebagai pedoman supaya memudahkan peserta mempelajari langkahlangkah pengoperasian Corel Draw dalam kegiatan pelatihan. Pelatihan desain grafis ini dimulai dengan pengenalan tool-tool yang ada di Corel Draw X7. Penjelasan terhadap fiturfitur dan cara penggunaannya dilakukan sesuai langkah-langkah di dalam modul pelatihan. Hal ini bertujuan agar para peserta dapat mengikuti setiap proses penggunaan dengan baik dan tepat.

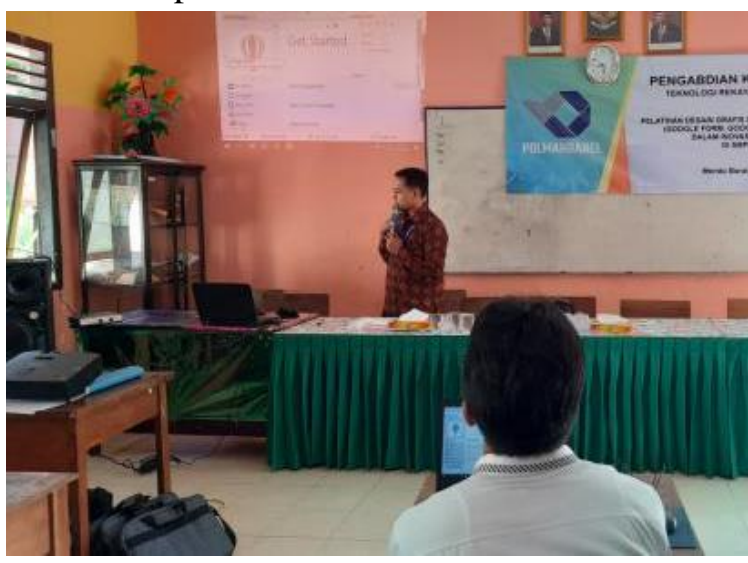

Gambar 2. Penyampaian Materi

Gambar 2 memperlihatkan saat narasumber mengenalkan aplikasi desain grafis Corel Draw X7 dan menjelaskan fungsi terhadap tool-tool yang ada di dalamnya.

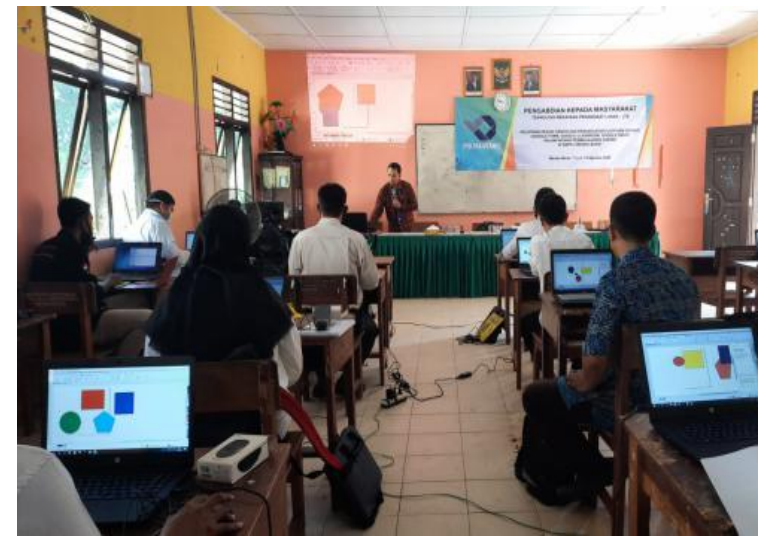

Gambar 3. Praktik Pembuatan Objek Dasar
Gambar 3 memperlihatkan kegiatan pelatihan yang diikuti oleh para guru SMP Negeri 3 Mendo Barat. Materi yang diberikan tentang pembuatan bentuk dasar seperti kotak, lingkaran dan segilima.

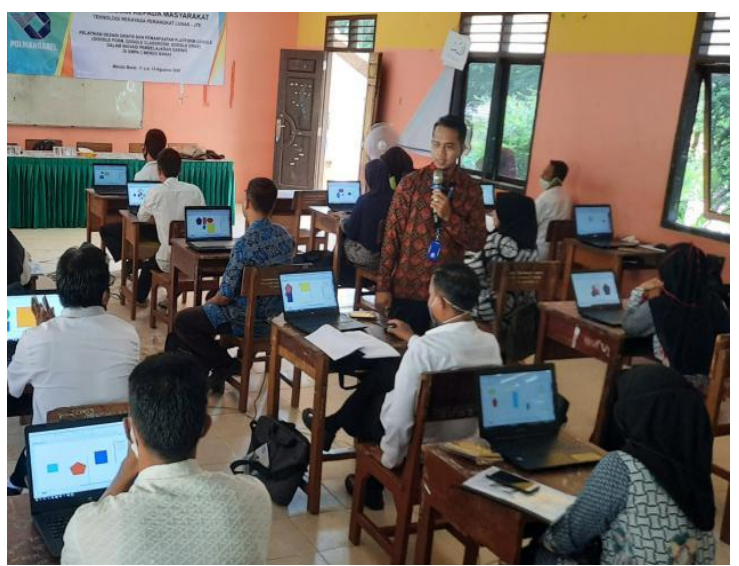

Gambar 4. Pendampingan Langsung Pada Peserta Pelatihan

Jika peserta mengalami kesulitan dalam pengoperasian Corel Draw X7, selain menggunakan modul pelatihan, maka dilakukan pendampingan secara langsung oleh narasumber agar peserta lebih mudah memahami cara pengoperasian dan memecahkan permasalahan.

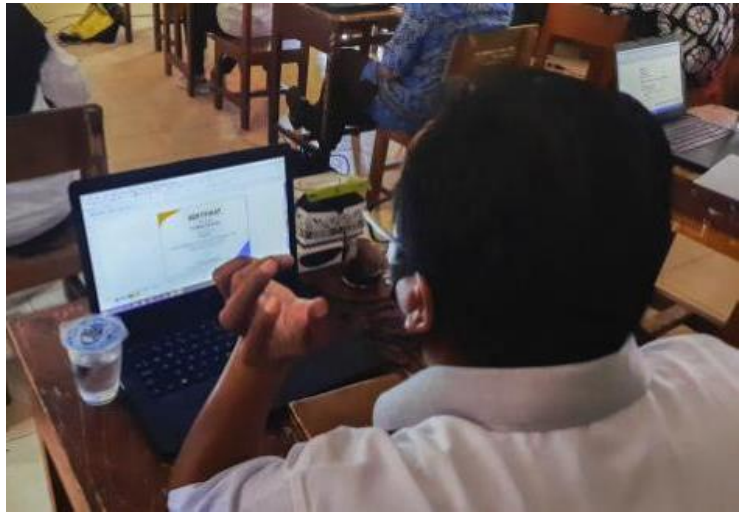

Gambar 5. Pembuatan Sertifikat

Gambar 5 memperlihatkan proses kegiatan tugas mandiri pembuatan sertifikat yang diberikan dosen Politeknik Manufaktur Negeri Bangka Belitung. Tugas mandiri ini 
diberikan dengan tujuan agar para guru memiliki keterampilan membuat sertifikat. Melalui keterampilan ini diharapkan para guru mampu membuat gambar atau ilustrasi pendukung untuk bahan ajar.

Setelah pelatihan dan pendampingan yang dilakukan terdapat peningkatan kemampuan yang dimiliki para peserta dalam pengoperasian aplikasi Corel Draw X7. Peningkatan yang terlihat antara lain, peserta dapat mengatur posisi tulisan dengan shortcut pada keyboard, kerapian tata letak konten menjadi lebih baik, penggunaan jenis tulisan yang tepat, memberikan kombinasi warna, dan mampu mengubah bentuk dasar menggunakan shape tool dengan baik.

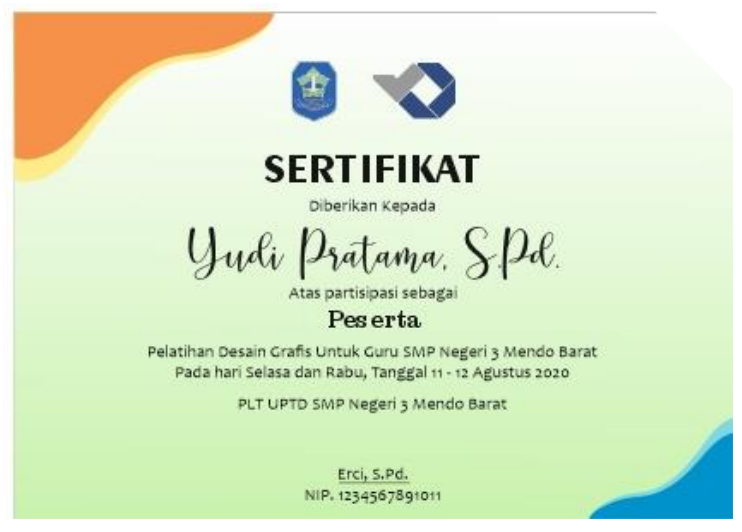

Gambar 6. Contoh Hasil Desain

Gambar 6 di atas adalah hasil akhir desain dari salah satu peserta pelatihan desain grafis. Melalui pelatihan ini, peserta dapat membuat sertifikat dengan kreatifitasnya masing-masing dan peserta memiliki kemampuan atau kompetensi dalam bidang desain grafis.

\section{KESIMPULAN}

Pelaksanaan kegiatan pelatihan desain grafis ini berjalan dan baik. Peserta dibekali modul tercetak dan e-modul sebagai panduan mandiri. Dampak dari pelatihan ini adalah bertambahnya keterampilan para guru di bidang desain grafis. Hal itu dibuktikan dengan hasil kreatifitas dari tugas mandiri yang telah diberikan. Sehingga dengan keterampilan tersebut, para guru dapat memanfaatkan kemajuan teknologi informasi untuk memudahkan proses penyampaian materi pembelajaran secara klasikal maupun daring.

Untuk kegiatan seperti pelatihan di bidang teknologi informasi selanjutnya, perlu dipersiapkan perangkat komputer yang memadai dari segi performanya. Karena perangkat lunak khususnya desain grafis membutuhkan performa komputer yang cukup tinggi. Ketersediaan modul dan $e$-modul yang

lengkap untuk para peserta belajar mandiri diluar kegiatan pelatihan. Selain itu, jika waktu pelatihan cukup banyak, disarankan untuk memberikan satu materi tambahan sesuai permintaan para peserta.

Keberlanjutan dari kegiatan pengabdian kepada masyarakat ini adalah agar para guru dapat memanfaatkan keterampilan desain grafisnya untuk menyajikan materi pembelajaran yang kreatif dan inovatif bagi siswa. Supaya menambah minat siswa dalam belajar.

Pelatihan desain grafis ini merupakan salah satu metode dalam meningkatkan kompetensi guru di bidang teknologi informasi. Banyak pelatihan dengan materi berbeda yang dapat diselenggarakan untuk menambah kompetensi guru antara lain pelatihan video editing, sound editing, animasi dan pemanfaatan teknologi informasi lainnya. Tim PKM ini berharap dapat terjalin kerjasama yang baik dalam pengembangan kompetensi sumber daya manusia dengan SMP Negeri 3 Mendo Barat dan sekolah-sekolah lainnya.

\section{UCAPAN TERIMA KASIH}

Tim Pengabdian kepada Masyarakat Politeknik Manufaktur Negeri Bangka Belitung mengucapkan terimakasih sebesarbesarnya kepada:

1. Bapak Sugeng Ariyono, M.Eng., Ph.D., selaku Direktur Politeknik Manufaktur Negeri Bangka Belitung 
2. Bapak Abdul Rofik, S.Pd., selaku perwakilan dari Satuan Pengawas Sekolah kecamatan Mendo Barat

3. Ibu Erci, S.Pd., selaku Pelaksana Tugas UPTD SMP Negeri 3 Mendo Barat

4. P3KM Politeknik Manufaktur Negeri Bangka Belitung

5. Guru-guru SMP Negeri 3 Mendo Barat

6. Staff Laboratorium SMP Negeri 3 Mendo Barat

Atas kesempatan dan bantuannya baik secara teknis serta non teknis dalam pelaksanaan pelatihan desain grafis menggunakan Corel Draw X7 yang ditujukan kepada para guru di SMP Negeri 3 Mendo Barat.

\section{DAFTAR PUSTAKA}

Budiarto, S. P. (2019). Pelatihan Desain Grafis dan Multimedia di Sekolah Menengah Kejuruhan Persatuan Guru Republik Indonesia Banyuputih Situbondo. JPM (Jurnal Pemberdayaan Masyarakat), 4(1), 308-313. https://doi.org/10.21067/jpm.v4i1.3059

Habibati, H., Hasan, M., \& Fitri, N. R. (2019). Pengembangan Media Buletin Menggunakan Coreldraw X7 pada Materi Pencemaran Lingkungan. Jurnal Pendidikan Sains Indonesia, 7(1), 23-33. https://doi.org/10.24815/jpsi.v7i1.13514

Harianto, W., \& Wiguna, A. S. (2020). Pelatihan Corel Draw Untuk Perangkat Desa. MARTABE : Jurnal Pengabdian Masyarakat, 3, 1-4.

Lisnawita, L., Lucky Lhaura Van FC, \& Musfawati. (2020). Pelatihan Desain Grafis Untuk Meningkatkan Kreatifitas Siswa. Dinamisia : Jurnal Pengabdian Kepada Masyarakat, 4(2), 231-235. https://doi.org/10.31849/dinamisia.v4i2.3 406

Raafi'udin, R., Hananto, B., \& Dewi, C. N. P. (2020). Peningkatan Desain Grafis Untuk Meningkatkan Kreatifitas Dan
Menambah Daya Saing Masyarakat Kecamatan Pasar Minggu Jakarta Selatan. SULUH: Jurnal Abdimas, 2(AGUSTUS), 70-77. https://doi.org/https://doi.org/10.35814/su luh.v2i1.1570

Rais, R., Afriliana, I., \& Budihartono, E. (2017). Peningkatan Ketrampilan Multimedia CorelDraw Di SMK Assalafiyah kota Tegal. Jurnal Pengabdian Masyarakat Progresif Humanis Brainstorming, 1(1), 55-61. https://doi.org/10.30591/japhb.v1i1.689

Rozaq, A., Hardinto, R. K., Yunida, R., Mujiarto, S., \& Jauhari, M. F. (2020). Pelatihan Desain Grafis Untuk Pemberdayaan Pemuda Karang Taruna Desa Karyabaru Kecamatan Barambai Kabupaten Barito Kuala Provinsi Kalimantan Selatan. Jurnal IMPACT: Implementation and Action, 2(1). https://doi.org/10.31961/impact.v2i1.742

Sari, M., Rahman, A., \& Yuridka, F. (2016). Pelatihan Design Grafis Coreldraw X4 Sebagai Penunjang Pembelajaran Bagi Guru Pada SMAN 1 Sungai Tabuk. AlIkhlas, 2, 34-38.

Slameto, Sulasmono, B. S., \& Wardani, K. W. (2017). Peningkatan Kinerja Guru Melalui Pelatihan Beserta Faktor Penentunya. Jurnal Pendidikan Ilmu Sosial, 27(2), 38-47.

http://journals.ums.ac.id/index.php/jpis/ar ticle/view/5718

Sujono, \& Roziqin, M. K. (2013).

Pelatihan Dasar Desain Grafis (Corel Draw) Pembuatan Poster di MI Subulussalam Pucangsimo

Bandarkedungmulyo Jombang. 53(9), 1689-1699.

Syafri, Edi; Endrizal, N. (2013). 101 Tip \& Trik Coreldraw 2018. Journal of Chemical Information and Modeling, 53(9), 1689-1699. 
Yenny Desnelita. (2019). PKMS Pelatihan

Desain Grafis Menuju Wirausaha

Bagi Pemuda RT.03 RW.04

Kelurahan Umban Sari. Dinamisia :

Jurnal Pengabdian Kepada

Masyarakat, 3(2), 266-272.

https://doi.org/10.31849/dinamisia.v3i

2.3424 